\title{
Tobacco control for all? The Belgian case
}

\author{
Pierre G. Bizel'
}

$\mathrm{E}$ uropean Union Member States are, by now, implementing the European Tobacco Products Directive (TPD) 2014/401. This directive marks a significant milestone in the fight against tobacco use in Europe. This success has been the result of a joint effort by many that include lobbyists, media, health professionals, lawyers and parliamentarians. Most of all it is European citizens who will benefit from TPD. All are mobilized through the WHO Framework Convention on Tobacco Control (FCTC) ${ }^{2}$, which gives relevant leverage on policies for signatory countries.

It might appear that the battle has been won when we see that legislation has been implemented, the public is informed, research has provided results, smoking-quit lines are available and affordable, non-smoker are protected by public policies and taxation policies are implemented. During most of the past forty years all these measures have contributed to the decline in smoking prevalence in many countries. However, the rate of decline has become slower and hence it is clear that we have still not reached out to all the people suffering from the ravages of tobacco use. Should we therefore be satisfied, let down our guard and be contented with this slow decline in prevalence? What is the reality?

In Belgium, much of this reduction in the prevalence of tobacco use can be attributed to long-term policies, most of them adopted during the last twenty years at the federal and regional level ${ }^{3,4}$ such as:

- restrictive legislation on access to tobacco products (sales), advertising, protection of non-smokers at the work place and in public spaces, and a gradual increase in taxation;

- support of tobacco-dependence services, through a multifactor approach including systematic health care professional advice and participation of specialists through assistance centres;

- adoption of health promotion policies, encouraging protective factors related to addiction, through the improvement of $i$ the skills of young people and their families.

Thus in Belgium, a social process to denormalize tobacco use has been implemented and produced definite results. For instance, in the province of Wallonia, smoking prevalence is currently at $25.2 \%$ (daily smokers and occasional smokers) while in the northern part of the country the prevalence is even less, at $21.9 \% \%^{5}$. Of course, the prevalence rates are still high and a third of all male deaths related to ill health are still tobacco related ${ }^{6,7}$.
The situation of the province of Wallonia is quite illustrative. The state of health of the population is still poor and is largely determined by the high incidence of chronic conditions (cardiovascular diseases and cancers, lung problems, mental health), resulting from the high prevalence of risk factors in this population ${ }^{8}$.Its difficult socio-economic context is partly due to the decline of heavy industries (coal, metallurgy, textiles) and a high unemployment rate $(20 \%)$, with the most disadvantaged social groups in terms of income, level of education, housing, family context being the most affected. Specifically, three factors (smoking, unbalanced diet, physical inactivity) account for much of the morbidity of this population?

In this context, it is important to stress that the prevalence of tobacco use has remained unchanged (at 34\%), in the lowest income group between 1997 and 2013, whereas it has fallen substantially (from $26 \%$ to $16 \%$ ), in the highest income group. The prevalence gap between the lowest and the highest income groups has in fact almost doubled from $7.8 \%$ to $14.1 \%^{10}$. Furthermore, through the years, the global decline in smoking among the most disadvantaged social groups seems to have slowed down since tobacco control measures have sometimes little effect within these subpopulations ${ }^{11}$ This 
means that the issue of social inequality in tobacco use remains dramatic $^{12}$.

Clearly, denormalization of tobacco use is not a reality for all, as measures taken in the past seem to have been ineffective in reducing this widening gap despite a long process of reflection, often based on evidence, supported by politicians and public opinion.

The paradox deserves attention, it needs to be identified and analysed, together with all professional groups involved in tobacco control and also with the different population groups themselves. How can measures be universally applied, precisely enough, appropriately and also efficiently to regulate tobacco use for all?

An analysis of Belgian tobacco control policies could serve as a starting point of a global strategy, since the persistence of smoking habits and the resistance of some social groups to prevention policies seem to be both related to several combined factors ${ }^{13}$ :

- Low tobacco prices, especially for roll -our -own tobacco, do not encourage smokers to quit or deter non-smokers from starting.

- The easy accessibility of tobacco products at almost every supermarket cashier desk for example, or at newsstands, as well as the persistence of point of sale advertising, all make tobacco products highly visible.

- The inadequacy of specific cessation programs directed at groups of the population with high prevalence.

- Prohibition policies for tobacco use in public places and at work, transport, restaurants, have a low impact on these populations because of unemployment, social isolation and low purchasing power.

- Large tobacco industry groups with effective marketing and lobbying capacities are poised to interfere in the preparation of new legislations.

- Local authorities may be hardly aware that within the scope of their functions they can protect non-smokers and participate in the denormalization of tobacco use.

When it is time for the Belgium federation and its federate entities (regions) to consider prevention plans and health system reforms it is essential that priorities and proposals come firstly from the public health domain, based on the duly identified health needs of the population. In the objective to reduce prevalence to an "endgame" scenario in Belgium, it is now highly recommended that smoking prevention strategies focus on social health inequalities and include all levels of authorities from federal to local, towards shared programmes.

\section{REFERENCES}

1. Directive 2014/40/EU of the European parliament and of the council of 3 April 2014. Available at: http://ec.europa.eu/health/ tobacco/docs/dir_201440_en.pdf (accessed 2 May 2017)

2. World Health Organization. WHO Framework Convention on Tobacco Control. Available at: http://apps.who.int/iris/bitstre am/10665/42811/1/9241591013.pdf?ua=1/ (accessed 2 May 2017)

3. Coalition Nationale contre le tabac. Le gouvernement fédéral en échec face au tabac, Revue Education Santé, n³ 313, 2015

4. EuropeanCommission, Overview of smokefree legislation and its implementation in the EU. Brussels, European Commission, 2013

5. Enquête Nationale de Santé (HIS 2013). Institut Scientifique de Santé Publique (IPH) Bruxelles, Belgique 2013. Available at: https://his.wiv-isp.be/FR/SitePages/Accueil.aspx (accessed 2 May 2017)

6. Smoking prevalence and attributable disease burden in 195 countries and territories, 1990-2015: a systematic analysis from the Global Burden of Disease Study 2015, Institute for Health Metrics and Evaluation, University of Washington, The Lancet, 2017. doi: http://dx.doi.org/10.1016/S0140-6736(17)30819-X

7. Van Oyen H., The effect of smoking on the duration of life with and without disability, Belgium 1997-2011, Unit of Survey, Life Styles and Chronic Diseases, Directorate Public Health and Surveillance, Scientific Institute of Public Health, Brussels, WIV-ISP Editor, 2014. doi: 10.1186/1471-2458-14-723

8. Service Public de Wallonie, Tableau de bord de la santé en Wallonie, SPW Editor, 2009

9. Observatoire de la santé du Hainaut - Santé en Hainaut $n^{\circ} 12$, Tableau de bord de la santé 2016, 2016

10. Gisle L. La consommation de tabac. Dans: Gisle L, Demarest S (éd.). Enquête de santé 2013. Rapport 2 : Comportements de santé et style de vie. WIV-ISP, Bruxelles, 2014

11. OECD/EU (2016), Health at a Glance: Europe 2016 - State of Health in the EU Cycle, OECD Publishing, Paris. doi : 10.1787/9789264265592-en

12. Mendis A. Towards an equity lens approach. Tobacco Prevention and Cessation 2017. doi: https://doi.org/10.18332/tpc/68836

13. World Bank. Tobacco control at a glance. Washington, World Bank, 2003

CONFLICT OF INTEREST The authors have completed and submitted the ICMJE Form for Disclosure of Potential Conflicts of Interest and none were reported.

FUNDING

There was no source of funding for this research

PROVENANCE AND PEER REVIEW

Not commissioned;

internally peer reviewed 